\title{
EL CUARTO DE ATRÁS DE CARMEN MARTIIN GAITE: OTRA HISTORIA
}

Marcela Romano*

\section{Introducción}

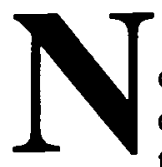

os proponemos en este trabajo reconstruir los caminos de una mirada, de una mirada que a su vez construye su propia representación en torno a los hechos de la guerra y posguerra españolas. El texto elegido es El cuarto de atrás, de Carmen Martín Gaite, el cual, escrito en 1978 y por lo mismo distanciado de otros relatos más coetáneos a la contienda, ofrece una versión singular y novedosa de este fragmento de la historia de España. Instalada plenamente dentro del linaje de las escrituras de género "femenino", la dinámica de la novela parece romper continuamente con la represión de los discursos legitimados desde la autoridad de un único sentido y establece su propia legalidad a través de la discontinuidad, la diseminación semántica, las ausencias. las máscaras, una focalización particular y disidente con respecto a los mundos en ella referidos. Los principios constructivos de esta novela se mueven y la atraviesan desde el lugar anfibio y escurridizo de la frontera, posición estratégica que perfila sus modos de constitución en aspectos muy puntuales: los diferentes y superpuestos niveles de ficcionalización que configuran la fábula (en su relación texto / extratexto, vigilia / sueño, pasado / presente, vida / ficción / meta-ficción etc.), el desarrollo arborescente de la voz (desplegada en múltiples

* Universidad Nacional de Mar del Plata, Argentina 
voces que remiten a otros tiempos, a otros lugares, a otros niveles de realidad), el montaje polémico de códigos discursivos (el relato fantástico, la autobiografía, el ensayo histórico, la novela rosa, entre otros) que discuten entre sí, de poética a poética, y dentro de sí, con sus convenciones específicas, poniendo no sólo en cuestión las leyes canónicas de cada género, sino la virtualidad referencial de todo discurso 1 .

Este último aspecto resulta clave para leer El cuarto de atrás como un relato histórico de orientación ostensiblemente transgresora y heterodoxa. $\mathrm{La}$ novela se sitúa en este sentido como un camino de alternativa: frente a la historia "oficial" (adjetivo que, más allá de su connotación ideológica, involucra en nuestro trabajo a la tradición cristalizada en torno a los discursos históricos, ficcionales o no), la guerra y la posguerra son narradas aquí por una voz femenina, atenta al despliegue de la memoria, de los sueños, de las sensaciones, del azar. Esta voz expone su versión de los hechos en su conversación con un interlocutor, y su relato a su vez ingresa en la historia como un discurso de ficción sobre el cual la misma novela reflexiona. El suyo es, finalmente, un relato que atiende no al recorte fáctico, cronologizado e individualista de la historiografía tradicional, sino que se mueve a los saltos en los pliegues sutiles de la vida privada, del imaginario femenino de la época, de la experiencia de los héroes cotidianos sin nombre ni contorno.

Explorar el funcionamiento y el sentido de este modo otro de escribir la historia es el objetivo de las páginas que siguen.

\section{Historia y poética "femenina": claves de su constitución}

Frente a la enunciación neutra y presumiblemente "masculina" (hegemónica) de la historiografía tradicional novecentista, la voz histórica de $E l$ cuarto de atrás se recorta, según anticipamos en nuestra Introducción, como una voz "femenina". No sólo porque la protagonista-narradora es una mujer (una figuración autobiográfica, dicho sea de paso, de la misma autora), sino porque la dinámica de la enunciación misma se diseña como "femenina".

Sintagma polémico, surgido de un marco teórico todavía provisional, lo "femenino" en la literatura debe ser leído desde el "género" del discurso y no,

1 Al respecto puede consultarse nuestro artículo "El cuarto de atrás de Carmen Martín Gaite: una poética del margen", 1995. 
reductivamente, a través del "sexo" del autor. Como muy lúcidamente aclara Nora Domínguez,

leer el género implica leer los mecanismos de su construcción literaria, no realidades empiricas que se asocien directamente con el sexo de quien escribe. Leer el género no implica leer sólo lo que las mujeres escriben sino los modos en que se anudan sexualidad y discurso en cualquier texto literario y cómo se combinan con otro tipo de representaciones: de clase, políticas, etc. $^{2}$

Ya Julia Kristeva ha teorizado indirectamente en torno a estos problemas. Sus reflexiones acerca de los órdenes simbólico y semiótico, deudoras de las teorías psicoanalíticas de Jacques Lacan, iluminan el debate sobre escritura "femenina" desde una perspectiva no sexista. Sus trabajos sobre los textos "modernistas" (Láutreamont, Mallarmé, y, en general, el experimentalismo vanguardista) permiten comprender que lo "femenino" (semiótico) de los discursos se constituye como tal a partir de su posicionamiento marginal y subversivo respecto del orden lingüístico "simbólico" establecido institucionalmente:

Llamaremos simbólico al funcionamiento lógico y sintético del lenguaje y lo que, en las prácticas translingüísticas es asimilable al sistema de la lengua. Semiótico será, por el contrario $[\ldots]$ el ordenamiento de las pulsiones en tanto fracturas psicosomáticas; pero por otra parte y sobre todo, será semiótico el retorno de esas fracturas al sistema propiamente simbólico bajo el aspecto de ritmos, entonaciones, transformaciones lexicales, sintácticas. retóricas. Si el simbolismo asegura el límite y la unidad de una práctica significante, lo semiótico indica el efecto de lo que no podría ser captado como signo, significante o significado. ${ }^{3}$

En este sentido, El cuarto de atrás puede incluirse en este linaje de escrituras en cuanto se articula a partir de una dinámica fronteriza y marginal,

2 Cfr. DOMÍNGUEZ, Nora, 1993.

3 Cfr. KRISTEVA, Julia. Práctica significante y modo de producción. In: Julia Kristeva. 1985, p. 19-20. Estos problemas se encuentran especificamente planteados en Kristeva, 1974. 
de dominios borrosos, de voces superpuestas, de códigos cruzados. De modo que las circunstancias referidas en la novela nunca se constituyen en el estamento de un discurso ordenado, lineal, cronológica y racionalmente organizado (al modo de la ciencia y la novela históricas canónicas) sino que se desplazan a empujones, en polémica con otras tematizaciones y registros desplegados en el texto, lo que da como resultado una escritura historiográfica sui generis, fragmentaria y azarosa, activada desde una memoria también casual y escurridiza, que el lector tiene que leer tanto en las grietas de lo dicho como en las ausencias de lo no dicho. ${ }^{4}$ La narradora, a instancias de su misterioso entrevistador, pierde permanentemente el hilo de sus reflexiones, las cuales son retomadas páginas más adelante o bien nunca, lo que genera en la superficie textual multiplicidad de lagunas, de blancos, de cuestiones no resueltas, de pequeñas anécdotas sin desenlace:

- La historia de España, qué?

- Nada. Es que ahora, cuando estaba en la cocina...

La última frase la he dicho tan bajo que no debe haberla oído, se esfuma, se lleva las imágenes de mi infancia y de la infancia de mi madre. Ha vuelto a caer la cortina que defiende la puerta del cuarto de atrás. ${ }^{5}$

Estas estrategias de fragmentación aumentan su efecto si pensamos en el posicionamiento siempre provisional del discurso de la protagonista. Muchas de sus reflexiones pueden leerse indistintamente como recuerdo (monólogo interior) o confesiones en voz alta a su entrevistador, porque intencionadamente en el texto no existen marcas de diferenciación entre ambas modalidades. La ambigüedad y las estrategias que la despliegan constituyen el principio constructivo fundamental de la novela, narrada por una voz "femenina", contragramatical, formalmente disidente y "semiótica", que expone no la racionalidad del sistema argumentativo causa-efecto, sino la irracionalidad de una experiencia de la historia de España.

Esta experiencia individual (la de la narradora) se nos presenta siempre diferida en razón de la presencia de tres mediaciones: la memoria, la oralidad,

4 Cfr. al respecto de los mecanismos reconstructivos de la memoria el artículo de Trevor Lummis, 1991.

5 Cfr. GAITE, Carmen Martín. [1978]. El cuarto de atrás. Barcelona: Destino, 1990. De aquí en adelante las citas corresponden a esta edición. 
y el discurso escrito mismo como artificio (sobre el cual el texto se vuelve en su espejo metaficcional).

La protagonista activa su recuerdo de los hechos de la guerra y la posguerra a instancias de su entrevistador, un individuo misterioso que la visita a medianoche. Su percepción de los mismos no es coetánea, y, por añadidura, su memoria es falaz.

El recuerdo constituye, como sabemos, no la experiencia de lo vivido, sino su versión, idealizada por el tiempo y el espacio, mediatizada por el presente y las expectativas del futuro, una construcción subjetiva del pasado. Si a eso añadimos las "fugas" frecuentes de la protagonista, estamos ante una evocación de la guerra y posguerra españolas hecha de trozos y silencios. La misma narradora reconoce ese modo particular de recordar:

Hacía un poco de frío, el frío se acababa de deshelar, aunque de eso no estoy segura, creo que me equivoco, los frios mayores fueron cuando la guerra (...) se me han montado varias imágenes (...) Yo es que la guerra y la posguerra las recuerdo siempre confundidas... (p. 127)

Al mismo ticmpo, la enunciación insiste frecuentemente en que lo recordado no proviene de la zona luminosa de la racionalidad, de la vigilia, sino del "cuarto de atrás", del "desván del cerebro", del inconsciente, donde triunfan el azar, las medias palabras, los blancos:

...una especie de recinto secreto lleno de trastos borrosos, separado de las antesalas más limpias y ordenadas de la mente por una cortina que sólo se descorre de vez en cuando; los recuerdos que pueden darnos alguna sorpresa viven agazapados en el cuarto de atrás, siempre salen de allí, y sólo cuando quieren, no sirve hostigarlos... (p. 91)

El recurso a la oralidad - que hace de El cuarto de atrás una "metanovela del discurso oral", según la aplicación que hace Sobejano de la tipología de Robert Spires ${ }^{6}$ - contribuye sustantivamente a la figuración de esta poética "femenina" de la que venimos hablando. La oralidad es en sí misma, como la 
escritura, una "tecnología de la palabra" 6 que instrumenta, como aquélla, sus propios dispositivos de producción, circulación y recepción. En lo que al texto respecta, interesa destacar dos efectos de lectura que produce la ficción de la oralidad mediatizada por la entrevista ${ }^{7}$ : la inmediatez (en oposición a la escritura como elaboración diferida y estática), y la irrecuperabilidad (frente a la permanencia de aquélla). Inmediatez que supone, por una parte, matices tales como cotidianeidad, espontaneidad, trasunto más emotivo de la propia experiencia, desorden, reformulación permanente de lo dicho, continua movilidad semiótica. Por otra, el efecto de irrecuperabilidad sitúa el discurso de los personajes en el plano de las acciones y de los acontecimientos más que en las versiones de los mismos (como la escritura), lo que genera por un lado la sensación de que siempre se pierden datos (pérdida que la novela como tal conserva intencionadamente), y que lo dicho tiene una espesura, un contorno, un relieve que semióticamente se perfila mucho más allá del nivel verbal, en una pluralidad que la escritura recupera siempre de manera insuficiente, como una nueva mediación.

Experiencia mediada por la memoria, memoria activada por la entrevista oral, oralidad recogida en el discurso escrito. La novela pone una y otra vez de manifiesto el carácter representacional de la escritura, su capacidad para construir mundos alternativos, su estatuto eminentemente ficcional. Pero no sólo es ficcional, laberíntica, inquietante, la literatura. Lo son todos los discursos en cuanto tales, como traducción de lo real. La protagonista es una escritora y ante el desasosiego en que la embarca la literatura de creación, emprende el intento (fallido) de refugiarse en el "castillo" en apariencia seguro del ensayo histórico". Sin embargo, esta escritura, como tal, se vuclve un castillo de "papel", tan falaz como los otros 9 :

El cielo de papel se ha caído y me ha pillado debajo, los soldados del Archiduque Carlos corren por encima de mí, me van a

6 Cfr. para este concepto Walter Ong, 1987.

7 Decimos "efectos de lectura" y al hacerlo suponemos dos cuestiones: la oralidad es construida discursivamente por escrito, y por lo tanto, ficcionalizada, pero al mismo tiempo, en su reconstrucción se filtran, como vimos más arriba, los desajustes y grietas de su modo particular de representación.

8 Carmen Martín Gaite incursiona en este tipo de escritura en tres textos: El proceso de Macanaz, de 1969, Usos amorosos del dieciocho en España, de 1972, y Usos amorosos de la posguerra española, de 1978, éste último fuertemente ligado a la novela que trabajamos.

9 Gran parte de la historiografía contemporánea ha reflexionado sobre el carácter en gran medida ficcional del discurso histórico. Al respecto, resultan ya canónicas las tesis de Hayden White, 1992. 
aplastar, me enredo en los estandartes desgarrados, me asfixio, tengo que salir a buscar otro refugio, ninguno es seguro... (p. 59)

Ante la idea de que los hechos del pasado terminan de reconstruirse con piezas de un "rompecabezas que nunca podremos contemplar entero" (p. 54), la reflexión metahistórica de la narradora apunta a configurar, teórica y prácticamente, un modelo historiográfico marginal y subversivo respecto del institucionalizado:

El libro de la posguerra tengo que empezarlo en un momento de iluminación como el de ahora, relacionando el paso de la historia con el ritmo de los sueños, es un panorama tan ancho y tan revuelto, como una habitación donde cada cosa está en su sitio precisamente al haberse salido de su sitio... (p. 104)

Justamentc, es éste el proyecto cristalizado en la novela, transparentado en su particular poética, una poética de género "femenino", donde la subjetividad, los sueños, los deseos, la memoria, la palabra oral y la escrita se cruzan para dar a luz una versión de la historia de España distanciada de todo canon y de todo autoritarismo. Una discursividad otra en torno a lo real que no hace sino confirmar los sentidos anticipados en el epígrafe de Bataille: "La experiencia no puede ser comunicada sin lazos de silencio, de ocultamiento, de distancia..." (p. 8).

\section{Historia e ideología "femenina". La emergencia de lo otro}

La voz histórica de El cuarto de atrás se configura, según vimos, como poética, en un juego de estrategias y procedimientos que perfilan a partir de su montaje una enunciación "femenina", en los términos amplios con que definimos "género" líneas arriba.

Pero esta poética implica, a su vez, la emergencia de una ideología. Poética e ideología constituyen, conjuntamente, el discurso transgresor de la novela en la totalidad de sus niveles, y, específicamente, en su cualidad de representación histórica, el aspecto por nosotros escogido.

Cuando hablamos de "ideología" implicamos en este término definiciones tan vastas y abarcativas como "visión del mundo", "sistema de creencias y 
valores", "sistemas de representación", y un concepto operativo derivado, "imaginario", en el sentido con que se emplea en el ámbito de la historia intelectual y la sociocrítica, es decir, aquel "vasto campo de representaciones colectivas en donde se articulan (...) ideas, imágenes, ritos y modos de acción" "10.

Al entrar en este campo, que el plan de escritura de la novela se propone configurar con especial preponderancia, tenemos que definir el lugar de la enunciación y la materia del enunciado. Al hacerlo, ingresamos nuevamente en el campo de lo "femenino", pero entendido ya no como posicionamiento discursivo sino social, histórico, político. Porque quien habla en la novela es una mujer intelectual española, antifranquista (alter ego del sujeto empírico Carmen Martín Gaite), quien relata su experiencia privada de un recorte de la historia de España.

La escritura de la novela hace ostensible esta marca en la voz de una enunciación que fragmenta la historia elegida en perspectivas, miradas, fugas, que se distancian del discurso hegemónico de la historia oficial. Ya vimos en el apartado anterior cómo el cruce de estrategias textuales y los presupuestos teóricos que las orientan construyen un espacio escritural que evidencia las rupturas de todo sistema de representación verbal, incluído el discurso histórico. Que sea explícitamente una mujer la que asume el timón desvariado de este tránsito irrita aún más el sentido que cobran estas rupturas, en la medida en que la que habla es una voz socialmente marginada, silenciada, subvalorada. Por otra parte este "yo" - que es, de hecho, muchos yo desplegados - se apropia de un discurso, el de la historia, que a lo largo de los siglos ha llevado nombres de varón. Se apropia, claro está, para deconstruirlo, interrogarlo, problematizarlo. Por qué no, se dice la voz, reiteradamente en la novela, por qué no recordar, contar, escribir la historia a partir de los fantamas de la noche, de los sueños, de las sensaciones? Por qué no partir de mi experiencia, intransferible pero ejemplar a la hora de dar finalmente lugar a los héroes anónimos pero eficaces que todos somos? Por qué no recortar con preferencia las historias de la vida privada? Por qué no acudir al imaginario femenino de la época con el fin de iluminar los juegos del poder allí agazapado? ${ }^{11}$

Si, como dijimos, la materia de la historia "oficial" son los documentos, los archivos, los testimonios de personajes "notables", en El cuarto de atrás

10 Cfr. BACZKO, Bronislaw, 1991.

11 Estas problemáticas tienen hoy undudable actualidad en la historiografia contemporánea. Basta el ejemplo, por lo demás exitoso, de la Historia de la vida privada, dirigida por Philippe Aries y Georges Duby. 
aparecen mezcladas una y otra vez, las sensaciones íntimas, de apareamiento paradójico entre sí: miedo, frío, felicidad, libertad.

...Son para mí las sensaciones más envolventes de aquellos años: el miedo y el frío pegándose al cuerpo - 'no habléis de esto', 'tened cuidado con aquello', 'no salgáis ahora', 'súbete más la bufanda', 'no contéis que han matado al tío Joaquín', 'tres grados bajo cero'-, todos tenían miedo, todos hablaban del frío... (p. 57)

-La verdad es que yo mi infancia y mi adolescencia las recuerdo, a pesar de todo, como una época muy feliz. El simple hecho de comprar un helado de cinco céntimos (...) era una fiesta (...) Recuerdo el placer de chupar el helado despacito, para que durara..." (p. 70)

Detrás de estas apreciaciones perceptuales, y por lo tanto subjetivas y "privadas", se esconde sin embargo el dardo filoso de una conciencia crítica que compromete lo colectivo y lo público: la represión, el frío moral, el racionamiento. Nada es casual en los pliegues de un discurso que desde la historia individual salta a la social por las zonas oblicuas de una mirada en modo alguno inocente.

Por la puerta de la vida privada de la protagonista entran otras vidas privadas ligadas a los hechos de la contienda y el régimen franquista. Así la amiga semihuérfana, hija de "rojos" encarcelados durante la guerra (p. 57), y su amistad con el hijo del comandante (p. 62), revelan simultáneamente los paradigmas políticos y enfrentados de un corte histórico preciso:

Ese niño y la hija de los maestros encarcelados fueron mis primeros interlocutores secretos, con los dos tejí fantasías e historias, que aún recuerdo, pero nunca les hablaba a uno de otro, porque había intuido que ellos entre sí nunca iban a poder quererse, y lo más triste era que yo no entendía por qué; conocí el desgarrón, probado luego tantas veces, de las pasiones irreconciliables... (p. 62)

En esa línea aparecen fragmentos salpicados de víctimas cercanas, familiares o conocidas: la historia del churrero (p. 60), la el tío Joaquín (p. 115), 
siempre mezcladas con las aventuras y ensoñaciones felices de la protagonista, que, en sus lugares imaginarios y alternativo ${ }^{12}$ se resiste a pactar con el mundo exterior. Así en el viaje a Burgos, en busca del auto confiscado de su padre (acción situada en 1938), la destrucción dominante convive con los deseos de aventura de la joven protagonista: “...estoy con mi prima Angeles en la habitación de un hotel de Burgos, (...) nos parece maravilloso el lujo del cuarto (...), tenemos la ventana abierta, que entre el frìo, es una sensación incomparable de libertad..." (p. 110)

Pero al margen de estos pequeños héroes individuales, es la mujer como heroína colectiva la que cobra espesor en la dinámica de la novela, a través de la reconstrucción del vasto imaginario femenino de la guerra y la posguerra. La enunciación en este caso se vuelve casi ensayística o argumentativa, en un registro que supera lo anecdótico personal (aunque también lo incluya), para adentrarse en la generalidad de una historia, la de las mujeres españolas de su generación (incluida la misma Carmen Franco) en su vida cotidiana ${ }^{13}$. En esta reconstrucción, por momentos compacta, por momentos matizada, reaparecen con especial protagonismo los rituales de la moda de la época: las telas (p. 12-13), la perfumería (p. 14), los peinados (p. 65-67), las visitas a las modistas (p. 80-83). En todos los casos la descripción se detiene minuciosa y morosamente en dichos objetos y prácticas a través de una mirada analítica que busca exaltar el detalle y el matiz:

Las modistas se dividian en dos categorías principales: aquéllas de las que se temía que podían escabechar un traje y las que nunca lo escabechaban.(...) Las modistas que tenían fama de haber escabechado trajes en más de una ocasión era difícil que pasaran nunca del rango de costureras.(...) A las costureras (...) se les encargaban de preferencia las batas, las faldas de diario, la ropa interior, los uniformes de las criadas y los vestidos de los niños... (p. 81)

Junto con estos rituales exteriores convive la descripción también reiterada de las lecturas de las jovencitas de la época, centradas en un género por

12 La creación de lugares alternativos y opuestos a la oprobiosa España de la época es referida constantemente a lo largo de la novela: Bergai y Cunnigan, por ejemplo.

13 Estos aspectos han sido en parte, y posteriormente, desarrollados en el ya citado Usos amorosos... 
esos años exitoso: la novela rosa, de cuyos códigos se apropia en muchos momentos el texto para aludir a las peripecias de los protagonistas. Una y otra vez aparece mencionada Elisabeth Mulder y sus folletines publicados en la revista "Lecturas", junto con nombres como Eugenia Marlitt, Berta Ruck, Duhamel (p. 141), así como Carmen de Icaza, novelista "moderna" ya de la posguerra (p. 94). Mezcladas con los gestos de la narradora y el entrevistador aparecen diálogos entre personajes ejemplares de las mismas, como "Raimundo" y "Esperanza", o remedos de éstos, "Esmeralda" y "Alejandro", inventados en la adolescencia por la protagonista y su amiga.

Junto con este repertorio de ilusión y evasión que brindan las novelas rosas, aparecen, también abundantemente, los mitos cinematográficos de la época, en especial las jóvenes actrices con las que "C." parece identificarse: Leslie Howard, Norma Shearer, Shirley Temple, y, particularmente, Diana Durbin, emblema de la libertad y la felicidad soñada en contraste con la realidad terrible de España: "Había leído que, antes de ser actriz, iba al colegio en patines, con su cartera al hombro y - más difícil todavía - comiéndose un helado de limón. (...) esa aventura significaba para mí la alegoría de la libertad..." (p. 65)

Frente a estos mitos literarios y cinematográficos se yerguen, implacables, las enseñanzas de la Sección Femenina y su órgano de prensa específico, la revista "Y", con su propuesta particular en torno a la "felicidad", el sentido de la vida, y sus paradigmas de mujer y de familia ${ }^{14}$ :

La retórica de la posguerra se aplicaba a desprestigiar los conatos de feminismo que tomaron auge en los años de la República y volvía a poner el acento en el heroísmo abnegado de madres y esposas, en la importancia de su oscura y silenciosa labor como pilares del hogar cristiano (p. 93).

Frente a la ética oficial, que propicia la austeridad y el sacrificio, las heroínas de las novelas y del cine proporcionan la posibilidad de una vida otra. Son, en definitiva, un modelo contracultural (aun cuando hegemónico en cuanto a su consumo masivo) que se resiste a ser fagocitado por la cultura de la abnegación. En esa línea, con otras características, las canciones de Concha Piquer ofrecen por su parte un paradigma femenino también disidente: "Aquellas mujeres que andaban por la vida a bandazos y no se despedían de un novio

14 Remitimos para mayor detalle a Martín Gaite, 1984, cap. IIl. 
a las nueve y media en el portal de su casa, intranquilizaban por estar aludiendo a un mundo donde no campeaba lo leal ni lo perenne, eran escombros de la guerra..." (p. 153)

Porque de la guerra se trataba. Ante tanto edulcoramiento oficial, lo que El cuarto de atrás quiere mostrar es que la vida de las mujeres de posguerra al mismo tiempo pactó con y resistió al Régimen. Cuando no todo podía resolverse con una sonrisa, como pedía desde la Sección Femenina Pilar Primo de Rivera, allí estaban los ritos privados, las ficciones de la canción, de la novela, del cine. Vidas alternativas, expuestas y representadas, ante una vida real y pública que no ofrecía más que desolación y muerte.

\section{Conclusiones}

En este trabajo hemos recorrido sumariamente las alternativas de constitución del relato de la guerra y posguerra en El cuarto de atrás.

Lo hemos hecho en dos apartados que dan cuenta, creemos, de la articulación entre poética e ideología, texto y extratexto, ficción e historia. Ambos, conjuntamente, revelan el diseño de un discurso histórico otro, alternativo, que permite la emergencia de una mirada "femenina" sobre ese corte puntual de la historia de España.

El análisis del primer aspecto ha permitido demostrar la presencia de una voz "femenina", posicionada discursivamente como subversiva respecto de la lógica de los sentidos unívocos, a partir de una enunciación escurridiza cuyos modos de escenificación se revelan, asimismo, como construcciones aleatorias: la memoria, el discurso oral, el discurso escrito de la ficción. Mediaciones, todas ellas, que apelan a la emoción, los deseos, los sueños, los recuerdos semiinconscientes, para reconstituir un fragmento de la historia de España desde una perspectiva distinta pero no precisamente neutral.

El segundo apartado se ha concentrado en la configuración ideológica de esta voz, voz de mujer que revitaliza como documento imprescindible el imaginario femenino de la época, de las mujeres y sobre las mujeres, en su vida cotidiana. En la evaluación de este imaginario se ponen en escena, creemos, los pactos y las resistencias que desde lo cultural han perfilado el papel de este sector de la sociedad española que, en apariencia, no se limitó a "sonreir".

El cuarto de atrás se revela, entonces, doblemente disidente. Desde su discurso y desde sus ideologemas explícitos, busca contar otra historia, de otro modo, con otros temas, pero señalando, aunque oblicuamente, la misma barbarie, el mismo dolor, las mismas muertes. 
ROMANO, M. El cuarto de atrás de Carmen Martín Gaite...

\section{RESUMEN}

Este estudio abordará la construcción de la "otra" historia de la España franquista hecha por una mujer y explicar la inserción de la novela El cuarto de atrás en el género "femenino", cuya noción se apoyaría en la dinámica discursiva polifónica, caracterizada por tres aspectos puntuales: diferentes niveles de ficcionalización que configuran la fábula (texto / extratexto, vigilia / sueño, vida / ficción / metaficción etc); el despliegue de voces; la coocurrencia de diferentes códigos discursivos (autobiografia, ensayo histórico, relato fantástico, entre otros).

Palabras-clave: niveles de ficcionalización, polifonia, interrelación de códigos discursivos.

\section{RESUMO}

Este estudo pretende abordar a construção da "outra" história da Espanha franquista feita por uma mulher, e explicar a inserção do romance El cuarto de atrás no gênero dito "feminino", cuja conceituação estaria fundamentada na dinâmica discursiva polifônica, em que três aspectos seriam caracterizadores: os diferentes níveis de ficcionalização que configuram a fábula (texto / extratexto, vigília / sonho, vida / ficção / metaficção etc); o desdobramento das vozes; a co-ocorrência de diferentes códigos discursivos (autobiografia, ensaio histórico, relato fantástico, entre outros).

Palavras-chave: niveis de ficcionalizaçāo, polifonia, interrelação de códigos discursivos. 


\section{BIBLIOGRAFÍA}

BACZKO, Bronislaw. Los imaginarios sociales: memorias y esperanzas colectivas. Bueno Aires: Nueva Visión, 1991, p. 17.

DOMÍNGUEZ, Nora. Leer el género. Suplemento de Cultura de Página/12, p. 2-3, 14 de mar. de 1993.

KRISTEVA, Julia. Práctica significante y modo de producción. In: KRISTEVA, Julia et al. Travesía de los signos. Buenos Aires, Ediciones La Aurora, 1985. p. 19-20. . La révolution du langage poétique. Paris, Seuil, 1974.

LUMMIS, Trevos. La memoria. In: MOSS, W.; FRASER, R. et al. La historia oral. Buenos Aires: Centro Editor de América Latina, 1991, p. 83-101.

MARTÍN GAITE, Carmen. [1978]. El cuarto de atrás. Barcelona: Destino, 1990. . Usos amorosos de la España de posguerra. Barcelona: Anagrama, 1984.

$\widehat{\mathrm{ONG}}$, Walter. Oralidad y escritura: tecnologías de la palabra. México: Fondo de Cultura Económica, 1987.

ROMANO, Marcela. El cuarto de atrás, de Carmen Martín Gaite: una poética del margen. Confluencia, v. 10, n. 2, p. 23-34, primavera de 1995.

SOBEJANO, Gonzalo. Novela y metanovela en España. Insula, 512/513, p. 4, ago.-sep. 1989, p. 4.

WHITE, Hayden. Metahistoria: la imaginación histórica en la Europa del siglo XIX. México: Fondo de Cultura Económica, 1992. 